have significant genome-related research interests. Otsuka Pharmaceutical, for example, started sequencing cDNA in May 1993 and now has a team of 40 researchers working on genotype analysis. And Takeda, Japan's largest pharmaceutical company, linked up with SmithKline Beecham earlier this year, in part to gain access to the wealth of human sequence data that SmithKline has licensed from the US-based Human Genome Sciences (Nature Medicine 1, 500; 1995).

Takeda has chosen to adopt a different commercial strategy, deciding not to wait for a home-grown genome R\&D industry to develop in Japan, says Yukio Sugino, the company's advisor. "These new companies are not venture start-ups, the government is taking all the risk," says Sugino, who has been campaigning for Japanese companies to take a more venture-orientated approach to $R \& D$ in biotechnology.

The proposals have generally been welcomed by academics, although some researchers expect the new companies to face problems in recruiting qualified personnel in Japan. While others say the research objectives are poorly defined. "This is not the scientific way, the money comes first and then they decide what to do," says one researcher. Officials at both ministries are, however, reluctant to discuss specifics but say that detailed research objectives will be decided soon.

Meanwhile, government spending on genome research is increasing. Four research groups, each targeting different regions of the human genome, recently received new grants worth a total of $\$ 5.28$ million a year for three years for their sequencing projects from the Japan Information Center for Science and Technology, which is linked to the Science and Technology Agency.

Together, these groups, which make up the majority of Japan's human genome effort, will probably now be able to sequence 2 to 3 million base pairs a year, says Yusuke Nakamura, director of the Human Genome Center at Tokyo University, one of the four centres to receive the recent awards. However, he believes Japan should be contributing more to the international effort by sequencing 20 to 30 million base pairs a year. "When you look at total government spending in Japan, and compare it with that of other countries, Japan is spending very little on basic science and sequencing," Nakamura says.

RICHARD NATHAN

Tokyo

\title{
Terms set for commercializing gene therapy in Japan
}

An advisory panel to Japan's Ministry of Health and Welfare has announced safety guidelines for gene therapy, paving the way for Japanese researchers and drug companies to develop gene therapies commercially. The guidelines, which were developed by the ministry's Central Pharmaceutical Affairs Council's biotechnology committee, specify the methods of testing the safety of genes to be administered to patients, as well as the vectors used.

Companies wishing to import or to produce gene therapy materials, including vectors, are expected - not required - to file applications with the council. Teams conducting clinical trials for research purposes, as in Japan's first gene therapy trial at Hokkaido University earlier this year (Nature Medicine 1,856 ; 1995), will be exempted. Two government committees which consider safety and ethical issues already exist for screening applications. But the council's new safety guidelines, which are awaiting final approval, are the first to set the terms for safety and efficacy. They cover manufacturing methods for materials used in gene therapy, including vectors, preclinical trial safety testing and quality control.

Researchers involved in Japan's first gene therapy trial, which used an ex vivo approach to treat a 4-year-old boy suffering from adenosine deaminase (ADA) deficiency, relied heavily on data from the United States to establish the safety and efficacy of the retroviral vector involved. The vector was developed by the US National Institutes of Health and the company Genetic Therapy and was approved by the US Food and Drug Administration (FDA).

Some industry analysts in Tokyo cynically describe the new guidelines as "a truly excellent translation of the FDA guidelines." Health ministry officials acknowledge that the safety guidelines are based on those in the United States but hope they will help clarify how the ministry expects companies to proceed in this new area and, in doing so, will encourage commercial development.
Masamoru Hasegawa, managing director of DNAVEC, a recently established gene therapy research and development company (Nature Medicine 1, 291; 1995), set up with government backing by a consortium of seven large Japanese drug companies, welcomes the new guidelines. "They will make it is easier for us to design our experiments and develop vectors," he says.

One researcher in the field, however, says the new guidelines are nothing to get excited about as the Japanese authorities do not yet know how to check the safety and efficacy of vectors. What is really needed to take Japan's gene therapy efforts forward, he hospital that can specialize in clinical trials for advanced molecular medicine. He and some other researchers believe that this is the only way Japan can develop expertise in administering and understanding gene therapy.

The guidelines should, however, allow to go forward the planned clinical trial of three patients with HIV by researchers at Kumamoto University Hospital for Midori Juji (Green Cross), a blood product manufacturer in Osaka. Midori Juji has imported the technology, which involves the use of a vector based on a mouse leukaemia retrovirus carrying a full-length copy of the HIV-1 envelope protein (gp120), from Chiron Viagene in the United States.

The company is waiting for the guidelines to be officially adopted before submitting its application to the council to confirm the safety of the vector it plans to use. Researchers at the university have already made the necessary submissions to the two other relevant government committees at the Ministry of Education, Science, Sports and Culture and the health ministry. Approval there will enable Midori Juji to make a chikentodoke, a clinical trial submission, which will allow the trial finally to begin.

RICHARD NATHAN Tokyo 